\title{
mPer1 and mPer2 mutant mice show regular spatial and contextual learning in standardized tests for hippocampus-dependent learning
}

\author{
M. Zueger ${ }^{1, *}$, A. Urani ${ }^{1, *}$, S. Chourbaji ${ }^{1}$, C. Zacher ${ }^{1}$, \\ H. P. Lipp ${ }^{2}$, U. Albrecht ${ }^{3}$, R. Spanagel ${ }^{1}$, \\ D. P. Wolfer ${ }^{2}$, and P. Gass ${ }^{1}$ \\ ${ }^{1}$ Central Institute of Mental Health Mannheim (ZI), \\ University of Heidelberg, Germany \\ ${ }^{2}$ Institute of Anatomy, University of Zürich-Irchel, Zürich, and \\ ${ }^{3}$ Department of Medicine, Division of Biochemistry, University of Fribourg, Switzerland \\ Received January 21, 2005; accepted April 17, 2005 \\ Published online June 15, 2005
}

\begin{abstract}
Summary. Learning and memory, like most physiological processes, seem to be under the control of circadian rhythm. The recently cloned $m P e r l$ and $m P e r 2$ genes play an important role in the regulation of the circadian rhythm. In this study, we tested mPerl and mPer 2 mutant mice in two different learning and memory paradigms, a water-maze place navigation task and contextual fear conditioning. In both learning tests, the hippocampus is critically involved. None of these learning types were affected by the mutations, suggesting that mPer 1 and mPer 2 do not play a major role in the regulation of hippocampusdependent learning and memory.
\end{abstract}

Keywords: Clock genes, hippocampus, learning, knockout mice.

\section{Introduction}

Biological rhythms in mammals are controlled by biological clocks located in the central nervous system but also in peripheral non-neuronal tissues (Brown and Schibler, 1999; Dunlap, 1999; Cermakian and Sassone-Corsi, 2000). They are under the control of a central endogenous clock located in the suprachiasmatic nucleus (SCN) of the hypothalamus (Ralph et al., 1990). This central clock produces self-sustaining circadian rhythms that are synchronized by external cues such as the light-dark cycle (Weaver, 1998). This cycle is under the control of several genes, as it has first been demonstrated in Drosophila (Konopka

\footnotetext{
* Both authors made equal contributions to this paper
} 
and Benzer, 1971; Bargiello et al., 1984). These so-called period or per genes encode for proteins involved in the autoregulatory transcriptional feedback loops that maintain the endogenous rhythm on an approximately $24 \mathrm{~h}$ basis, even in the absence of environmental cues (Reppert and Weaver, 2001).

Three homologues of per have been discovered in mammals (Albrecht et al., 1997; Shearman et al., 1997; Zylka et al., 1998) and are called mPerl, mPer2 and $m P e r 3$. They are differentially expressed in an oscillatory manner during the day in the SCN (Shimomura et al., 2001) and also in other tissues (Sakamoto et al., 1998). Additionally, their expression in the SCN is activated by light stimulation (Albrecht et al., 1997; Shearman et al., 1997). Inactivation of each of the three per genes in mice has led to the conclusion that they all have distinct and non-redundant roles in the circadian system. mPer 2 mice display the strongest phenotype showing a disruption of their behavioral rhythm. These mutant animals have short period rhythms finally becoming arrhythmic in a constantly dark environment. In contrast, the mPer3 gene is not essential for circadian rhythm, since mutant mice for this gene display a rather normal behavioral rhythm. $m P e r 3$ is thought to play a buffering role in the protein-protein interactions among the essential clock proteins in the SCN (Shearman et al., 2000). The most recently targeted per gene, mPerl, seems to be less critical than mPer2, because the phenotype of mPerl knockout mice is milder than that of mPer2 mutants. mPerl is thought to be involved predominantly in peripheral clocks and/or in the output pathways of the SCN, and to exert its role via a posttranscriptional control (Bae et al., 2001; Cermakian et al., 2001; Zheng et al., 2001).

Circadian rhythms are thought to play a role in the processing and retention of information. It has been shown that disruption of the light-dark cycle can produce memory decrements in active and passive avoidance tasks (Holloway and Wansley, 1973; Davies et al., 1974; Fekete et al., 1985). In particular, hippocampus-dependent memory is affected by the disruption of the circadian organization in rats, as demonstrated in the Morris water-maze (Devan et al., 2001). A more emotional type of learning, fear conditioning, has also been shown to be dependent on the circadian time at which training and recall occur (Chaudhury and Colwell, 2002). A previous study has shown that mPerl knockout mice have a deficit in place preference conditioning (Abarca et al., 2002), which is considered as a hippocampus-dependent learning task (Meyers et al., 2003). Therefore, the aim of this study was to assess whether these mice have general deficits of hippocampus-dependent learning, or if the impairment previously observed is rather related to drug-dependent mechanisms.

\section{Material and methods}

\section{Animals}

All experiments were performed blindly on 3-6 months-old 129 SvEvBrd X C57Bl/6-Ty male and female mice with mixed background described previously $\left(\mathrm{mPerl}^{\mathrm{Brdml}}\right.$ and $\mathrm{mPer} 2^{\mathrm{Brdm} 1}$ designated here as mPerl and mPer2 mutants (Zheng et al., 1999, 2001). Each strain of mice (mPerl, mPer2 and wild type) was derived from several different breeding pairs, respectively, to avoid effects due to drifts in genetic background. Homozygous mutants as well as wild types were kept on a $12 \mathrm{~h}$ artificial light-dark cycle with light off from 6:00. Temperature and humidity were 
kept constant (temperature: $22 \pm 1{ }^{\circ} \mathrm{C}$; humidity: $55 \pm 5 \%$ ). Animals were housed in groups of three or four and provided with food and water ad libitum, except during behavioral experiments. All experiments were conducted during the dark cycle, i.e. during the animals' active phase. The same cohort of mice was tested first in the water-maze task and one week later in the open field, in accordance with previous experiments. The other cohort of mice subjected to fear conditioning was handled twice a day for the two weeks preceding the experiment in the same room where fear conditioning was performed as described earlier (Strekalova et al., 2003).

\section{Water-maze studies}

Morris water-maze studies (Morris et al., 1982) were conducted with a training protocol consisting of 6 training trials per day with 30-60 min inter-trial intervals. Circular pool (diameter: $150 \mathrm{~cm}$ ), platform $\left(14 \times 14 \mathrm{~cm}^{2}\right)$ and visual cues were identical as described previously (Wolfer et al., 1997; Gass et al., 1998; Balschun et al., 2003). With a video camera suspended above the center of the pool, the swim tracks of the mice were recorded and fed to an electronic imaging system recording the $x y$-coordinates (Noldus EthoVision 2.3). The following variables from the recorded paths were analyzed: time to find platform (s), length of swim path $(\mathrm{m})$, swim speed while moving $(\mathrm{m} / \mathrm{s})$, percent of time spent floating, percent of time spent within a rim of $22 \mathrm{~cm}$ from the wall (thigmotaxis), percent of time swimming in parallel to the wall, number of wall touches, percent of time in target quadrant, average distance to the target, percent of time spent in former target quadrant and other quadrants, and number of crossings over the former platform position and over the circles in control quadrants. Animals were trained for 5 days. Each mouse did a total of 30 trials. The position of the platform was kept unchanged for the first three days (18 trials, acquisition phase). On the fourth and fifth day the platform was placed in the opposite quadrant (12 trials, reversal phase). In each swim trial, mice were left in the pool until $120 \mathrm{~s}$ had elapsed or they found the platform. The first $60 \mathrm{~s}$ of the first trial during the reversal phase served as probe trial for spatial retention. Number of animals: wild type $=14$ ( 6 males, 8 females), $m$ Perl $=9$ ( 3 males, 6 females), $m$ Per $2=11$ ( 7 males, 4 females).

\section{Fear conditioning}

Contextual fear conditioning was done as previously described (Gass et al., 1998; Strekalova et al., 2003). Mice were individually placed into the conditioning chamber $\left(58 \times 30 \times 27 \mathrm{~cm}^{3}\right.$, TSE, Bad Homburg, Germany) and allowed to habituate for $2.5 \mathrm{~min}$ before being subjected to the unconditioned stimulus $(2 \mathrm{~s}$ of continuous footshock of $0.8 \mathrm{~mA})$. $24 \mathrm{~h}$ after training, context conditioning was assessed by measuring freezing, defined as a complete lack of movements besides respiration. Context learning was tested in the same plexiglas chamber that was used for training by measuring freezing for $5 \mathrm{~min}$. Number of animals: wild type $=8$ ( 4 males, 4 females), $m$ Perl $=8$ ( 4 males, 4 females $), m P e r 2=10$ ( 5 males, 5 females).

\section{Open field test}

The open field arena consisted of a circular base with a diameter of $150 \mathrm{~cm}$, a white plastic floor; the wall surrounding the base was made of $35 \mathrm{~cm}$ high white polypropylene. The arena was illuminated indirectly by diffuse room light (four $40 \mathrm{~W}$ bulbs resulting in 12 lux). Mice were placed near the sidewall and observed for $10 \mathrm{~min}$. The same procedure was repeated the following day, resulting in a total observation time of $20 \mathrm{~min}$, partitioned into four bins of $5 \mathrm{~min}$ for time course analysis. With a video camera suspended above the center of the arena, the tracks of the mice were recorded and fed to an electronic imaging system recording the $x y$-coordinates (Noldus EthoVision 2.3). Recorded tracks were divided into three motion states as described in Madani et al. (2003) and Zörner et al. (2003) according to criteria modified from Drai et al. (2001): 1.) Progression episodes were defined by velocity above the locomotion threshold of $8.5 \mathrm{~cm} / \mathrm{s}$ and a total distance moved $>5 \mathrm{~cm}$. Rapid decelerations deeper than $15 \mathrm{~cm} / \mathrm{s}$ were subtracted and classified as lingering (see below). 2.) Resting episodes were periods lasting $2 \mathrm{~s}$ or longer with smoothed speed values (averaging frame $0.5 \mathrm{~s}$ ) below the system noise level of $2.5 \mathrm{~cm} / \mathrm{s}$. 3.) The remaining time was classified as lingering episodes which correlated with exploratory behaviors 
such as brief stopping, sniffing, establishing snout contact with the substrate, looking around, stretch attend postures, rearing, or leaning against the wall. Because the tracking system also monitored apparent subject area, we estimated vertical activity by counting reductions of subject area deeper than $250 \mathrm{~mm}^{2}$ while the animal was not progressing (Madani et al., 2003; Zörner et al., 2003). To assess approach-avoidance behaviors, dwell time was broken down into three zones. The exploration zone was a circular center field comprising 50\% of the arena. In addition we defined a $7 \mathrm{~cm}$ wide wall zone and an intermediate zone comprising the remainder of the arena. To allow comparison of zones irrespective of their size, an index of zone preference was calculated using the formula $100 \% \times \mathrm{T}(100-\mathrm{C}) /[\mathrm{T}(100-\mathrm{C})+\mathrm{C}(100-\mathrm{T})]$, where $\mathrm{T}=\%$ time spent in the zone and $\mathrm{C}=\%$ of arena surface occupied by the zone (Madani et al., 2003). According to this formula, an index value of 0 indicated complete avoidance of the zone and a value of 100 maximal preference. Irrespective of zone size, a score of $50 \%$ would be obtained by a randomly moving animal. Number of animals: wild type $=14$ ( 6 males, 8 females), $m P e r l=9$ ( 3 males, 6 females), $m$ Per2 $=11$ ( 7 males, 4 females).

\section{Statistics}

Data were analyzed using 2-way-ANOVA with genotype (mPerl, mPer2, wild type) and gender as between subject factors. If we found a significant main effect of genotype $(\mathrm{p}<0.05)$, individual effects of the mPer1 and mPer2 mutation were resolved using partial comparisons with a Bonferroni adjusted significance threshold $(\mathrm{p}<0.025)$. We were not primarily interested in the analysis of gender differences. Nevertheless, the gender factor was included to check for genderdependence of genotype effects and to reduce unexplained variance within genotype groups. Unless explicitly mentioned, genotype effects were found to be statistically independent of gender. If appropriate, additional, within subject factors were included in the ANOVA design: a time factor to analyze learning and habituation effects in the water-maze task and open field, respectively, as well as a zone/place factor to evaluate spatial retention in the probe trial and zone preferences in the open field. All statistical calculations were done using Statview 5.0 for Windows.

\section{Results \\ mPer1 and mPer2 knockout mice show regular learning in the water-maze task}

Irrespective of their genotype (ANOVA: genotype ns, time (blocks of 2 trials) $\mathrm{p}<0.0001$, interaction $\mathrm{p}<0.032)$ the mice demonstrated an improvement of escape performance during the acquisition and reversal phase as revealed by decreasing swim path lengths (ANOVA time: mPer1 $\mathrm{p}<0.0001$, mPer2 $\mathrm{p}<0.0001$, wild type $\mathrm{p}<0.0001$; Fig. 1A). Also, all groups showed a similar transitory worsening of escape performance in response to platform relocation, indicating that they had developed a spatial strategy specifically adapted to the given platform location. Performance levels were very similar in all three groups: with respect to the path lengths needed to find the platform, no significant difference was found between wild type, mPerl and mPer 2 mice (ANOVA: genotype ns, time (blocks of 2 trials) $\mathrm{p}<0.0001$, interaction ns; Fig. 1A). During the probe trial, all three groups exhibited a significant preference for the trained platform position (Fig. 1B). Mutant mice did not statistically differ from wild type mice with respect to the time spent in the quadrant of the trained platform position (2-way-ANOVA: place (target vs. average of adjacent quadrants) $\mathrm{p}<0.0001$, genotype-place interaction ns; Fig. 1B) nor with respect to time spent in a target zone comprising $1 / 8$ of the pool surface 

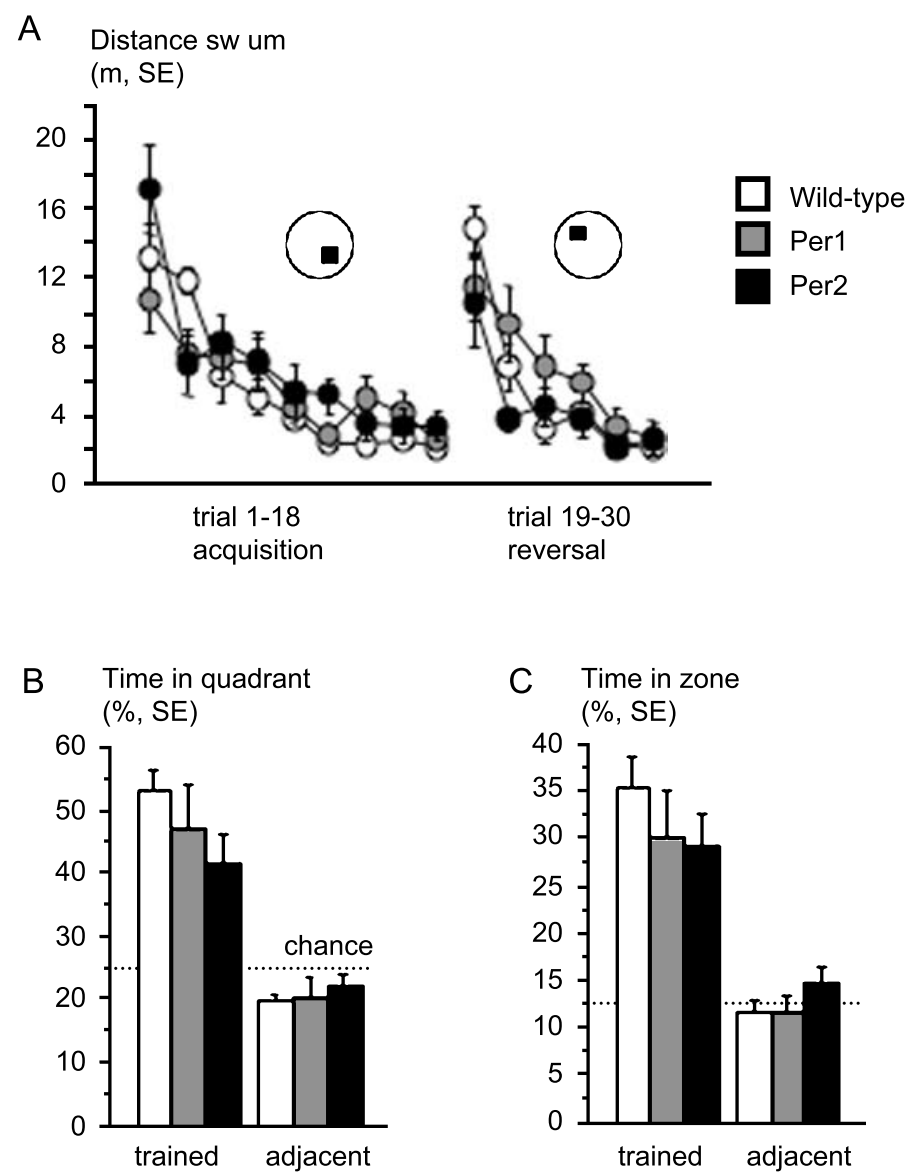

Fig. 1. Mice lacking $m P e r l$ or $m P e r 2$ genes did not show learning deficits in the water-maze test. A As judged by swim path length, escape performance varied between groups only during the beginning of the acquisition training but became similar as training progressed. All three genotypes demonstrated a significant improvement of escape performance during acquisition training. The three groups were indistinguishable with respect to escape performance during the reversal phase. B During the probe trial (first $60 \mathrm{~s}$ of reversal), all mice exhibited a significant preference for the trained goal position both with respect to time spent in the quadrant and $\mathbf{C}$ with respect to time spent in a target zone comprising $1 / 8$ of the pool surface

(ANOVA: place (target vs. average of control zones in adjacent quadrants) $\mathrm{p}<0.0001$, genotype-place interaction ns; Fig. 1C). Furthermore, no statistically significant differences were observed for all other parameters investigated, such as swim speed, thigmotaxis, number of wall touches and percentage of floating (data not shown). In summary, no significant differences were found in wild types, $m P e r l$ and $m P e r 2$ mice with respect to training performance (acquisition, reversal) or spatial retention (probe trial).

\section{Context conditioning is not affected by the absence of mPerl and mPer2}

Contextual fear conditioning is an associative (Pavlovian) learning paradigm that is dependent on both hippocampus and amygdala (Rogan and LeDoux, 


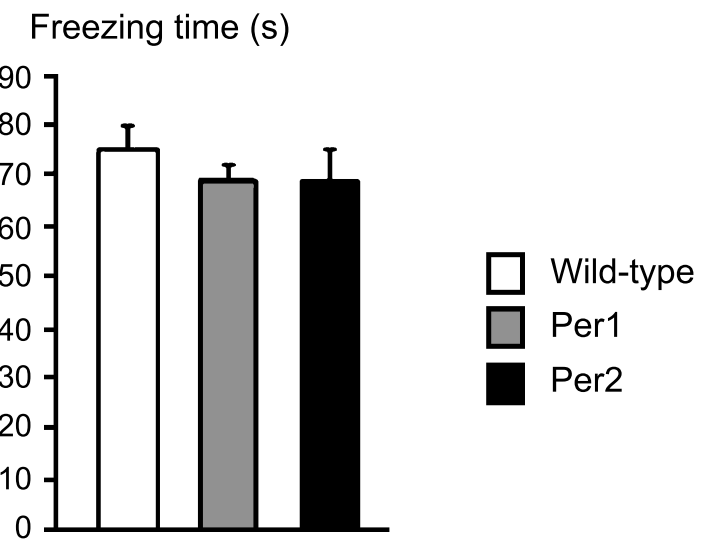

Fig. 2. Contextual fear conditioning revealed no difference in associative learning in mice lacking either $m P e r l$ or $m P e r 2$ gene, compared to wild type controls. Freezing time was similar in all three strains

1996; LeDoux, 2000). The amount of freezing (immobility) represents a correlate of fear-associated memory. During the $2.5 \mathrm{~min}$ training period, no differences were observed between the three groups (wild type, mPerl and mPer2) with respect to locomotion including freezing and shock sensitivity (data not shown). $24 \mathrm{~h}$ after training $m$ Per 1 mice, $m P e r 2$ mice and controls demonstrated similar freezing scores when investigated for context learning $\left(F_{2,25}=0.3272\right.$, p $>0.05$; Fig. 2).

\section{mPer2 knockout mice exhibit increased locomotor activity in the open field}

The open field test evaluates the general locomotor and exploratory behavior of mice exposed to a large open arena under dimmed light conditions. The three groups (wild type, mPerl and mPer2) differed with respect to total distance moved but were indistinguishable with respect to habituation of activity across observation periods (ANOVA: genotype $\mathrm{p}<0.0004$, time $\mathrm{p}<0.0001$, interaction ns). Post hoc analysis showed a similar behavior in mPerl as in wild type mice (Fig. 3). In contrast, mPer2 mutants moved longer distances than wild types (genotype $\mathrm{p}<0.0001$; Fig. 3A). This difference was due to an increase of progressive locomotion at the expense of lingering (ANOVA mPer2 vs. wild type: genotype $\mathrm{p}<0.0004$, motion-state $\mathrm{p}<0.0001$, interaction $\mathrm{p}<0.0001$; Fig. 3B). No such change was evident in mPer1 mice (ANOVA mPerl vs. wild type: genotype ns, motion-state $\mathrm{p}<0.0001$, interaction ns; Fig. 3B). In addition to their reduced horizontal lingering activity, mPer 2 mice also showed a reduction of estimated vertical activity (ANOVA: genotype $\mathrm{p}<0.0004$; mPerl vs. wild type ns, mPer2 vs. wild-type $\mathrm{p}<0.0001$; Fig. 3C). Calculation of zone preferences revealed that irrespective of genotype the mice showed strong avoidance of the center field and clear preference for the wall zone (ANOVA: zone $\mathrm{p}<0.0001$, genotype-zone interaction ns; Fig. 3D). 


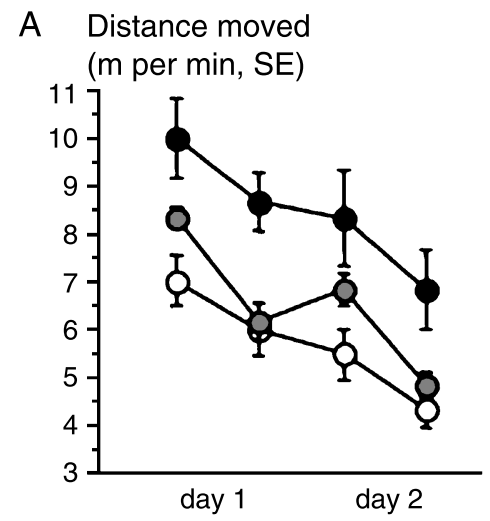

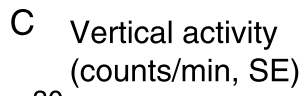

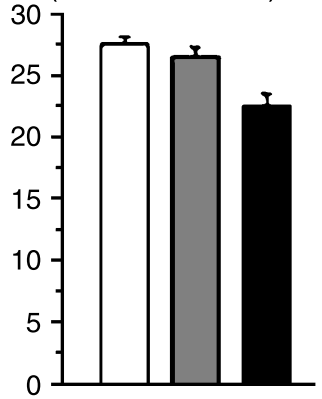

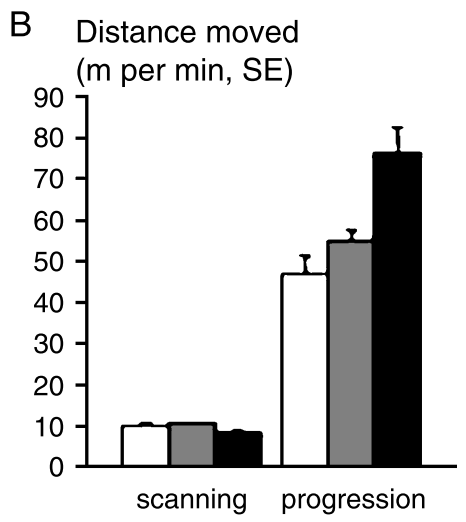

$\square$ Wild-type
$\square$ Per1
Per2

D Zone preference

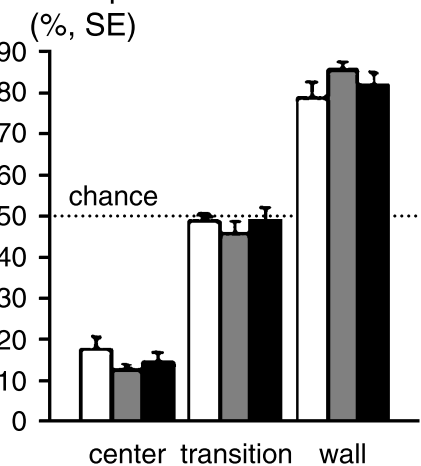

Fig. 3. Altered behavior of $m P e r 2$ mice in the open field. A The three groups differed with respect to total distance moved but were indistinguishable with respect to habituation of activity across observation periods. Post hoc analysis showed that $\mathrm{mPer} 2$ mutants but not $\mathrm{mPerl}$ mice moved longer distances than wild type mice. This difference was due to an increase of progressive locomotion at the expense of horizontal $(\mathbf{B})$ and vertical $(\mathbf{C})$ lingering movements. No such changes were evident in mPerl mice. D Zone preferences, and in particular, distance to center was indistinguishable between the 3 lines. ${ }^{* *}$ corresponds to $\mathrm{p}<0.01$

\section{Discussion}

Among the genes involved in circadian rhythm regulation, per genes have been cloned and mice carrying mutations of these genes have been generated (Zheng et al., 1999, 2001; Bae et al., 2001; Cermakian et al., 2001). The aim of the present study was to investigate if hippocampus-dependent learning and memory processes would be affected by such mutations. $m$ Perl and mPer 2 knockout mice did not differ from their wild type controls in spatial learning and memory in our water-maze procedure. They were also similar to the controls in contextual fear conditioning, which represents a more emotional type of memory. Thus, both spatial and contextual hippocampal learning do not seem to be affected by the mutations. The only behavioral difference observed was a mild hyperlocomotion in the open field test for $m P e r 2$ deficient mice. While we can 
not definitively rule out that the latter finding results from a drift in genetic background, this seems unlikely, because only one mutant line (mPer2) exhibited hyperlocomotion. Furthermore, hyperlocomotion was not consistently observed under all test situations but only in the open field, e.g. not during training for fear conditioning and not during place preference conditioning in earlier experiments (Abarca et al., 2002). With respect to the main focus of the present study, however, the absence or presence of mild hyperlocomotion did not correlate or interfere with the good learning capabilities observed in $m P e r 2$ deficient mice in the water-maze task as well as in context or place-preference conditioning.

The fact that mPerl and mPer 2 genes do not seem to be implicated in the learning and memory processes investigated here can not be explained by a physiological absence of these genes in the brain areas involved in these processes. Indeed, in addition to its expression in the SCN, mPerl and mPer2 mRNAs are constitutively present in several brain areas including the hippocampus (Albrecht et al., 1997; Shieh, 2003). The hippocampus is an important brain area for spatial learning, so if mPerl and mPer 2 would play a role in learning and memory processes in this area, their absence in mutant mice would lead to an effect. In addition to the hippocampus, contextual fear conditioning involves the amygdala (Kim and Fanselow, 1992; Maren et al., 1997; LeDoux, 2000; Anagnostaras et al., 2001; Wallenstein and Vago, 2001), where both mPerl and mPer2 are also expressed (Shieh, 2003). Again, if these genes played a role, their absence should have induced a deficiency in this learning paradigm.

However, despite of these observations, the literature reveals that learning and memory, like most physiological processes, seem to be subject to modulatory regulation by the circadian system. The ability to learn to associate a specific time and place with a food reward has been confirmed in many species, e.g. insects, fishs, birds and mammals (Beling, 1929; Moore et al., 1989; Biebach et al., 1991; Mistlberger et al., 1996; Carr and Wilkie, 1997; Marchant and Mistlberger, 1997; Reebs and Lague, 2000; Aragona et al., 2002; Pizzo and Crystal, 2002). Many studies have also demonstrated diurnal differences in the ability of animals to acquire or recall a memory task. Both acquisition and retrieval are affected by phase, even if only through the level of alertness and activity present at that phase. The phase difference between training and testing also affected performance: retrieval of a learned task was better 24 hours after the training than at other time points (Holloway and Wansley, 1973). Phase shifting the light-dark cycle also impaired passive (Tapp and Holloway, 1981; Fekete et al., 1985) and active (Fekete et al., 1985) avoidance memory. This $24 \mathrm{~h}$ rhythm performance was abolished after destruction of the SCN (Stephan and Kovacevic, 1978). Acquisition of a shuttle avoidance task and 8 -arm radial mazes were better in animals during the dark period (Pagano and Lovely, 1972; Hauber and Bareiss, 2001). Active avoidance task acquisition was also time-dependent, since it was quicker during specific times of the day than at other times of the day or night (Holloway and Wansley, 1973; Bialik et al., 1984). Conditioned emotional responses were acquired much faster when animals were trained repeatedly at the same time of day than when they were 
trained at random times. The extinction was also faster when unreinforced tests were made at the same time of day (Stroebel, 1967).

Regarding the tests used in the present study, both water-maze and fear conditioning have been shown to be dependent on circadian rhythm. First, phase shifting of the light-dark cycle, which causes temporary rhythm disruption, impaired spatial memory consolidation in rats in the water-maze task without affecting the acquisition (Devan et al., 2001). These results show that cognitive retention in a spatial memory test can be disrupted by phase-shifting circadian rhythms. Second, mice acquired the fear conditioning faster during day than during night. The recall was also higher during day, irrespective of the time of training, and extinction of this training was faster in mice trained at night. Each of these diurnal rhythms persisted when animals were maintained in constant darkness, indicating that the fear conditioning process is dependent on endogenous rhythms (Chaudhury and Colwell, 2002).

The apparent discrepancy between our results and the literature can be explained by several ways. It may be due to species differences, variations in training protocols, or behavioral paradigms that make use of different neural substrates. First, the water-maze study has been done in rats and not in mice. Perhaps learning performances of mice in the water-maze are less affected by the circadian rhythm. Moreover, it was postulated that the type of memory affected by phase shifting is a long-term consolidation that takes place during slow-wave sleep (Devan et al., 2001). mPer2 and mPerl mice have no altered homeostatic sleep regulation implying that these genes may not be important in this particular phase of the learning and memory process (Kopp et al., 2002). Second, the rhythm-dependence of fear conditioning in C57B1/6 mice depends on the training intensity (Chaudhury and Colwell, 2002). In our case, the intensity used $(0.8 \mathrm{~mA})$ was higher than the one the latter authors used $(0.3 \mathrm{~mA})$, which may explain why fear conditioning was not affected in $m P e r 1$ and $m P e r 2$ mutant mice. Third, none of the per mutant mouse lines is completely arrhythmic (Zheng et al., 1999; Shearman et al., 2000; Cermakian et al., 2001). This may be due to a partial redundancy in the function of these genes and the nonmutated genes could thus partially compensate for the loss of the third one. In consequence, the reason why the knockout mice tested here show no deficiency in learning may be due to compensatory mechanisms involving the two other per genes. Fourth, mutant mice were kept in a normal dark-light cycle. They behave normally in such conditions: they lose their circadian rhythm only under constant darkness. However, spatial and contextual learning - which depend on visible cues - could not be tested under constant darkness in our laboratory conditions. The latter argument could even be discussed in a more generalized way: one can not exclude, that per knockout mice would exhibit a learning and memory phenotype under other or even more refined test conditions. In the present study, however, we aimed to investigate the effect of per genes using hippocampus-dependent learning and memory paradigms that our laboratories have used to test thousands of mice. Our water-maze and fear conditioning protocols are capable of detecting major deficits of learning and memory. These standard experiments would have shown, if per genes have a direct and major impact on learning and memory - which was the main purpose of the present 
study. The normal findings of our experiments do not exclude a more subtle phenotype, possibly detectable by modified protocols. However, the detection of such a phenotype under very specific conditions only - such as constant darkness - was not the major aim of this study. We rather wanted to clarify, whether the behavioral alterations of conditioned place-preference learning in per mutant mice are drug-related - which is very important for the field of addiction-related learning - or rather caused by general hippocampus-dependent learning impairments. Our findings clearly favour the former hypothesis, suggesting that mPerl and mPer 2 do not play a major role in the regulation of hippocampus-dependent learning and memory.

\section{Acknowledgements}

This work was supported by grants from the Deutsche Forschungsgemeinschaft (GA 427/4-2 and B3/SFB636 to P.G.) and the NCCR "Neural Plasticity and Repair".

\section{References}

Abarca C, Albrecht U, Spanagel R (2002) Cocaine sensitization and reward are under the influence of circadian genes and rhythm. Proc Natl Acad Sci USA 99: 9026-9030

Albrecht U, Sun ZS, Eichele G, Lee CC (1997) A differential response of two putative mammalian circadian regulators, mper1 and mper2, to light. Cell 91: 1055-1064

Anagnostaras SG, Gale GD, Fanselow MS (2001) Hippocampus and contextual fear conditioning: recent controversies and advances. Hippocampus 11: 8-17

Aragona BJ, Curtis JT, Davidson AJ, Wang Z, Stephan FK (2002) Behavioral and neurochemical investigation of circadian time-place learning in the rat. J Biol Rhythms 17: $330-344$

Bae K, Jin X, Maywood ES, Hastings MH, Reppert SM, Weaver DR (2001) Differential functions of mPer1, mPer2, and mPer3 in the SCN circadian clock. Neuron 30: $525-536$

Balschun D, Wolfer DP, Gass P, Mantamadiotis T, Welzl H, Schutz G, Frey JU, Lipp HP (2003) Does cAMP response element-binding protein have a pivotal role in hippocampal synaptic plasticity and hippocampus-dependent memory? J Neurosci 23: 6304-6314

Bargiello TA, Jackson FR, Young MW (1984) Restoration of circadian behavioural rhythms by gene transfer in Drosophila. Nature 312: 752-754

Beling I (1929) Ueber das Zeitgedaechtnis der Bienen. Z vergleichende Physiol 9: 259-338

Bialik RJ, Pappas BA, Roberts DC (1984) Deficits in conditioned avoidance responding following adrenalectomy and central norepinephrine depletion are dependent on postsurgical recovery period and phase of the diurnal cycle. Behav Neurosci 98: 847-857

Biebach H, Falk H, Krebs JR (1991) The effect of constant light and phase shifts on a learned time-place association in garden warblers (Sylvia borin): hourglass or circadian clock? J Biol Rhythms 6: 353-365

Brown SA, Schibler U (1999) The ins and outs of circadian timekeeping. Curr Opin Genet Dev 9: 588-594

Carr JA, Wilkie DM (1997) Rats use an ordinal timer in a daily time-place learning task. J Exp Psychol Anim Behav Process 23: 232-247

Cermakian N, Sassone-Corsi P (2000) Multilevel regulation of the circadian clock. Nat Rev Mol Cell Biol 1: 59-67

Cermakian N, Monaco L, Pando MP, Dierich A, Sassone-Corsi P (2001) Altered behavioral rhythms and clock gene expression in mice with a targeted mutation in the Period1 gene. EMBO J 20: 3967-3974

Chaudhury D, Colwell CS (2002) Circadian modulation of learning and memory in fearconditioned mice. Behav Brain Res 133: 95-108 
Davies JA, Navaratnam V, Redfern PH (1974) The effect of phase-shift on the passive avoidance response in rats and the modifying action of chlordiazepoxide. Br J Pharmacol 51: 447-451

Devan BD, Goad EH, Petri HL, Antoniadis EA, Hong NS, Ko CH, Leblanc L, Lebovic SS, Lo Q, Ralph MR, McDonald RJ (2001) Circadian phase-shifted rats show normal acquisition but impaired long-term retention of place information in the water task. Neurobiol Learn Mem 75: $51-62$

Drai D, Kafkafi N, Benjamini Y, Elmer G, Golani I (2001) Rats and mice share common ethologically relevant parameters of exploratory behavior. Behav Brain Res 125: 133-140

Dunlap JC (1999) Molecular bases for circadian clocks. Cell 96: 271-290

Fekete M, van Ree JM, Niesink RJ, de Wied D (1985) Disrupting circadian rhythms in rats induces retrograde amnesia. Physiol Behav 34: 883-887

Gass P, Wolfer DP, Balschun D, Rudolph D, Frey U, Lipp HP, Schutz G (1998) Deficits in memory tasks of mice with CREB mutations depend on gene dosage. Learn Mem 5: 274-288

Hauber W, Bareiss A (2001) Facilitative effects of an adenosine A1/A2 receptor blockade on spatial memory performance of rats: selective enhancement of reference memory retention during the light period. Behav Brain Res 118: 43-52

Holloway FA, Wansley RA (1973) Multiple retention deficits at periodic intervals after active and passive avoidance learning. Behav Biol 9: 1-14

Kim JJ, Fanselow MS (1992) Modality-specific retrograde amnesia of fear. Science 256: 675-677

Konopka RJ, Benzer S (1971) Clock mutants of Drosophila melanogaster. Proc Natl Acad Sci USA 68: 2112-2116

Kopp C, Albrecht U, Zheng B, Tobler I (2002) Homeostatic sleep regulation is preserved in mPer1 and mPer2 mutant mice. Eur J Neurosci 16: 1099-1106

LeDoux JE (2000) Emotion circuits in the brain. Annu Rev Neurosci 23: 155-184

Madani R, Kozlov S, Akhmedov A, Cinelli P, Kinter J, Lipp HP, Sonderegger P, Wolfer DP (2003) Impaired explorative behavior and neophobia in genetically modified mice lacking or overexpressing the extracellular serine protease inhibitor neuroserpin. Mol Cell Neurosci 23: 473-494

Marchant EG, Mistlberger RE (1997) Anticipation and entrainment to feeding time in intact and SCN-ablated C57BL/6j mice. Brain Res 765: 273-282

Maren S, Aharonov G, Fanselow MS (1997) Neurotoxic lesions of the dorsal hippocampus and Pavlovian fear conditioning in rats. Behav Brain Res 88: 261-274

Meyers RA, Zavala AR, Neisewander JL (2003) Dorsal, but not ventral, hippocampal lesions disrupt cocaine place conditioning. Neuroreport 14: 2127-2131

Mistlberger RE, de Groot MH, Bossert JM, Marchant EG (1996) Discrimination of circadian phase in intact and suprachiasmatic nuclei-ablated rats. Brain Res 739: 12-18

Moore D, Siegfried D, Wilson R, Rankin MA (1989) The influence of time of day on the foraging behavior of the honeybee, Apis mellifera. J Biol Rhythms 4: 305-325

Morris RG, Garrud P, Rawlins JN, O'Keefe J (1982) Place navigation impaired in rats with hippocampal lesions. Nature 297: 681-683

Pagano RR, Lovely RH (1972) Diurnal cycle and ACTH facilitation of shuttlebox avoidance. Physiol Behav 8: 721-723

Pizzo MJ, Crystal JD (2002) Representation of time in time-place learning. Anim Learn Behav 30: 387-393

Ralph MR, Foster RG, Davis FC, Menaker M (1990) Transplanted suprachiasmatic nucleus determines circadian period. Science 247: 975-978

Reebs SG, Lague M (2000) Daily food-anticipatory activity in golden shiners. A test of endogenous timing mechanisms. Physiol Behav 70: 35-43

Reppert SM, Weaver DR (2001) Molecular analysis of mammalian circadian rhythms. Annu Rev Physiol 63: 647-676

Rogan MT, LeDoux JE (1996) Emotion: systems, cells, synaptic plasticity. Cell 85: 469-475

Sakamoto K, Nagase T, Fukui H, Horikawa K, Okada T, Tanaka H, Sato K, Miyake Y, Ohara O, Kako K, Ishida N (1998) Multitissue circadian expression of rat period homolog (rPer2) 
mRNA is governed by the mammalian circadian clock, the suprachiasmatic nucleus in the brain. J Biol Chem 273: 27039-27042

Shearman LP, Zylka MJ, Weaver DR, Kolakowski LF Jr, Reppert SM (1997) Two period homologs: circadian expression and photic regulation in the suprachiasmatic nuclei. Neuron 19: $1261-1269$

Shearman LP, Jin X, Lee C, Reppert SM, Weaver DR (2000) Targeted disruption of the mPer3 gene: subtle effects on circadian clock function. Mol Cell Biol 20: 6269-6275

Shieh KR (2003) Distribution of the rhythm-related genes rPERIOD1, rPERIOD2, and rCLOCK, in the rat brain. Neuroscience 118: 831-843

Shimomura H, Moriya T, Sudo M, Wakamatsu H, Akiyama M, Miyake Y, Shibata S (2001) Differential daily expression of Per1 and Per2 mRNA in the suprachiasmatic nucleus of fetal and early postnatal mice. Eur J Neurosci 13: 687-693

Stephan FK, Kovacevic NS (1978) Multiple retention deficit in passive avoidance in rats is eliminated by suprachiasmatic lesions. Behav Biol 22: 456-462

Strekalova T, Zorner B, Zacher C, Sadovska G, Herdegen T, Gass P (2003) Memory retrieval after contextual fear conditioning induces c-Fos and JunB expression in CA1 hippocampus. Genes Brain Behav 2: 3-10

Stroebel CF (1967) Behavioral aspects of circadian rhythms. Proc Annu Meet Am Psychopathol Assoc 55: 158-172

Tapp WN, Holloway FA (1981) Phase shifting circadian rhythms produces retrograde amnesia. Science 211: 1056-1058

Wallenstein GV, Vago DR (2001) Intrahippocampal scopolamine impairs both acquisition and consolidation of contextual fear conditioning. Neurobiol Learn Mem 75: 245-252

Weaver DR (1998) The suprachiasmatic nucleus: a 25-year retrospective. J Biol Rhythms 13: $100-112$

Wolfer DP, Muller U, Stagliar M, Lipp HP (1997) Assessing the effects of the 129/Sv genetic background on swimming navigation learning in transgenic mutants: a study using mice with a modified beta-amyloid precursor protein gene. Brain Res 771: 1-13

Zheng B, Larkin DW, Albrecht U, Sun ZS, Sage M, Eichele G, Lee CC, Bradley A (1999) The mPer2 gene encodes a functional component of the mammalian circadian clock. Nature 400: $169-173$

Zheng B, Albrecht U, Kaasik K, Sage M, Lu W, Vaishnav S, Li Q, Sun ZS, Eichele G, Bradley A, Lee CC (2001) Nonredundant roles of the mPer1 and mPer2 genes in the mammalian circadian clock. Cell 105: 683-694

Zörner B, Wolfer DP, Brandis D, Kretz O, Zacher C, Madani R, Grunwald I, Lipp HP, Klein R, Henn FA, Gass P (2003) Forebrain-specific trkB-receptor knockout mice: behaviorally more hyperactive than depressive. Biol Psychiatry 54: 972-982

Zylka MJ, Shearman LP, Weaver DR, Reppert SM (1998) Three period homologs in mammals: differential light responses in the suprachiasmatic circadian clock and oscillating transcripts outside of brain. Neuron 20: 1103-1110

Authors' address: P. Gass, MD, Central Institute of Mental Health Mannheim, J 5, 68159 Mannheim, Germany, e-mail: gass@as200.zi-mannheim.de 